\title{
Umblikal Kateter İlişkili Portal Ven Trombozu: Bir Merkez Deneyimi
}

\section{Umbilical Catheter=Associated Portal Vein Thrombosis: A Center Experience}

\author{
$\underline{\text { Nilüfer MATUR OKUR }} \underline{1}^{(\mathbb{D})}$, Muhammet ASENA ${ }^{2}$ (D) , Kıymet ÇELIK ${ }^{1}$ (D) ,Nurettin OKUR ${ }^{3}$
}

\begin{abstract}
1 Sağlık Bilimleri Üniversitesi Gazi Yaşargil Eğitim ve Araştırma Hastanesi, Neonatoloji Bölümü, Diyarbakır / Türkiye 2 Sağık Bilimleri Üniversitesi Gazi Yaşargil Eğitim ve Araştırma Hastanesi, Çocuk sağlığı ve HastalıklarıBölümü, Diyarbakır/ Türkiye 3 Diyarbakır Çocuk Hastalıkları Hastanesi, Çocuk hematolojisi ve onkoloji Bölümü, Diyarbakır / Türkiye
\end{abstract}

Öz.

Amaç: Yenidoğan yoğun bakım ünitelerinde giderek artan sıklıkta invaziv girişimler yapılmaktadır. Özellikle preterm bebeklere sıkıkla umblikal kateterler takılmaktadır. Bu çalışmanın amacı kliniğimizde takılan umblikalkateterlerin portal ventrombozu (PVT) ile ilişkisini ve risk faktörlerini belirleyebilmektir.

Materyal ve metod: Retrospektif olarak 01 Ekim 2017-31 Aralık 2018 tarihleri arasında kliniğimiz yenidoğan yoğun bakım ünitesinde izlenen gestasyon yaşı 32 hafta ve altında olan, umblikal kateter takılan ve en az 6 saat boyunca kateter takılı olan preterm bebekler çalışmaya dahil edildi. Umblikal ven kateteri (UVK) takılan hastaların taburculuk öncesi PVT açısından yapılan portal venöz doppler ultrasonografi (USG) sonuçları ile perinatal risk faktörleri ve kateter ile ilgili özellikler değerlendirildi.

Bulgular: 142 hastaya UVK takıldı. 118 hastanın doppler USG sonucuna ulaşıldı. On beş $(\% 9,9)$ hastada doppler USG ile PVT saptandı. PVT saptanan hastaların hiçbirinde klinik bulgu yoktu. PVT saptanan hastaların ortalama gestasyon yaşı ve doğum ağırlı̆ı, PVT saptanmayan hastalardan daha düşüktü. On dört hastada portal venin sol dalında tromboz saptanırken, bir hastada ana portal vende tromboz saptandı.Tromboz saptanan bir hastada annede gestasyonel diyabet mevcuttu. PVT saptanan hastaların geç neonatal sepsis ve bronkopulmoner displazi oranları daha yüksekti, hastanede yatış süresi daha uzundu. Yine bu grupta kateterin alçak yerleşim oranı daha fazla, kateter kalış süresi ise diğer gruba göre daha uzundu.

Sonuç: Umblikal ven kateterizasyonu PVT gelişimi için önemli bir risk faktörüdür. UVK takılan, özellikle düşük doğum ağırıkı hastalar PVT açısından portal doppler USG ile değerlendirilmelidir.

Anahtar Kelimeler: Portal ven, Preterm, Tromboz

Abstract

Background: Invasive procedures are increasingly used in neonatal intensive care units. Umbilical catheters are frequently attached to preterm babies. The aim of this study is to determine the relationship and risk factors of umbilical catheters inserted in our clinic with portal vein thrombosis (PVT).

Materials and Methods: We retrospectively evaluated preterm infants with a gestational age of 32 weeks and below, who had a umbilical vein catheter (UVC) inserted in our neonatal intensive care unit between 01 October 2017 and 31 December 2018, and who had a catheter inserted for at least 6 hours. UVC inserted cases were evaluated for portal venous doppler ultrasonograpy (USG) examination before discharge. Perinatal risk factors and properties related to catheter were evaluated.

Results: A total of 142 patients underwent UVC insertion. Doppler USG results of 118 patients were achieved. In $15(9.9 \%)$ cases, portal vein thrombosis was detected by doppler USG. None of the patients with PVT had clinical findings. The mean gestational age and birth weight were lower in patients with PVT. Thrombosis was detected in the left branch of portal vein in 14 patients and thrombosis in the main portal vein in one patient. In a patient with PVT, gestational diabetes was present in the mother. Patients with PVT had higher rates of late neonatal sepsis and bronchopulmonary dysplasia, and the length of hospitalization was longer. In this group, the low placement rate of the catheter was higher, and the length of catheter stay was longer than other group. Conclusions: Umbilical vein catheterization is an important risk factor for the development of PVT. Especially low birth weight infants with UVC should be evaluated with portal doppler USG for PVT.

Keywords: Portal vein, Preterm, Thrombosis
Sorumlu Yazar I

Corresponding Author

Nilüfer MATUR OKUR

Sağlık Bilimleri Üniversitesi

Gazi Yaşargil Eğitim ve Araştırma

Hastanesi.

Diyarbakır / Türkiye

Tel:05065360059

e-mail: n.matur@hotmail.com

Geliş tarihi / Received: 05.05.2019

Kabul tarihi / Accepted: 30.10.2019

DOI: 10.35440/hutfd.560646

Çalışma 27.Ulusal Neonatoloji Kongresi'nde poster olarak sunulmuştur. 


\section{Giriş}

Potansiyel olarak tromboz riski taşımasına rağmen, umblikal kateterler yenidoğan yoğun bakım ünitelerinde (YBÜ) sık kullanılmaktadır. Bugün yatış yapılan hastaların yaklaşık \%15'ine ve doğum ağırlığı 1000 gram ve altındaki hastaların \%50'den fazlasına umblikal ven kateteri takılmaktadır (1). Umblikal kateterler damar duvarı epiteline zarar vererek platelet kümelenmesine ve fibrin oluşumuna neden olabilir. Umblikal ven kateteri takılan yenidoğanlarda portal ven trombozu (PVT), portal hipertansiyon ve komplikasyonları ile ilişkili bulunmuştur (2). Ultrasonografi (USG) kateter pozisyonunu ve trombozu saptamada kullanışlı bir yöntemdir. Umblikal kateter ilişkili PVT sıkığını saptamak oldukça zordur. Çalışmalarda umblikal venöz kateter ilişkili portal venöz tromboz insidansı \%1,3 ile 43 arasında değişmektedir (3).

$\mathrm{Bu}$ çalışmanın amacl; merkezimizde uygun yerleştirimiş umblikal kateter ve prenatal risk faktörlerinin PVT ile ilişkisini saptayabilmektir.

\section{Materyal ve metod}

Retrospektif olarak 01 Ekim 2017-31 Aralık 2018 tarihleri arasında kliniğimiz yenidoğan yoğun bakım ünitesinde izlenen gestasyon yaşı 32 hafta ve altında olan, umblikal kateter (5F ve $3.5 \mathrm{~F}$ umblikal kateter; vygon, Ecouen, France) takılan ve en az 6 saat boyunca kateter takılı olan preterm hastalar çalışmaya dahil edildi. Kliniğimizde umblikal kateter takılan hastalar taburculuk öncesi portal venöz doppler incelemesi yapılarak tromboz açısından değerlendirimektedir. Umblikal ven kateteri takılması sonrası kontrol direk batın grafisi ile umblikal ven kateter yerinin uygunluğu kontrol edilmektedir. Kateterin proksimal ucu 6-9. torasik vertebra arasında ise yüksek yerleşimli, 2-4 lomber vertebralar arasında ise alçak yerleşimli olarak tanımlanmaktadır.

Major konjenital anomalileri olan hastalar çalışmaya dahil edilmedi. Antenatal ve perinatal risk faktörleri değerlendirildi. Umblikal ven kateteri takılan hastalardan PVT olan ve olmayan hastalar gruplandırıldı. Hastaların demografik verileri, tromboz için risk faktörleri ve kateter ilişkili faktörler retrospektif olarak değerlendirildi.

Bronkopulmoner displazi (BPD), postkonsepsiyonel 36. hafta sonrası kalıcı bir oksijen gereksinimi olarak tanımlandı (BPD Jope A) (4). Şiddetli premature retinopatisi (ROP), bir oftalmolog tarafından yaşamın 28 günü itibariyle uygulanan ve uluslararası sınıflamaya göre 3-5. sınıflar olarak kategorize edilen bir test ile teşhis edildi (5).

Geç neonatal sepsis; postnatal 72 saatten sonra gelişen sepsis olarak tanımlandı.

Sağlık Bilimleri Üniversitesi Gazi Yaşargil Eğitim ve Araştırma Hastanesi Etik Kurul'unda onay alındı (karar no:246).

\section{Istatistiksel analiz}

Hastalardan elde edilen veriler bilgisayar ortamına aktarı- larak sayısallaştırıldı. İstatistiksel analizler, SPSS (Statistical Package for the Social Sciences) 21.0 istatistiksel Paket kullanılarak yapıldı. $p<0.05$ değeri istatistiksel açıdan anlamlı kabul edildi. Ölçüm değerlerinin normal dağılıma uygunlukları grafiksel olarak ve Shapiro- wilk testi ile incelendi. Sonuçlar ortalama \pm standart sapma veya ortanca (minimum-maksimum) olarak verildi. Sürekli değişkenler için bir $t$ testi veya Mann-Whitney $U$ testi uygulandı. Nominal değişkenler için $X 2$ testi veya Fisher exact testi uygulandı.

\section{Bulgular}

Çalışma periyodu boyunca ünitemize yatırılan $\leq 32$ ve $\leq 1250$ gram hasta sayısı 173 'tü. Kırk iki hastaya umblikal ven kateteri takıldı. 118 hastanın doppler ultrasonografi sonucuna ulaşıldı. On beş $(\% 9,9)$ hastada doppler USG ile PVT saptandı. On dört hastada portal venin sol dalında tromboz saptanırken, bir hastada ana portal vende tromboz saptandı. PVT saptanan hastaların hiçbirinde klinik bulgu yoktu. Umblikal kateter takılan hastaların ortalama gestasyon haftası $28.4 \pm 3$ hafta ve ortalama doğum ağıllğı $1115 \pm 285$ gramdı.

Tablo 1. Hastaların demografik karakteristikleri

\begin{tabular}{|c|c|c|c|}
\hline & $\begin{array}{l}\text { PTV olan } \\
(n=15)\end{array}$ & $\begin{array}{l}\text { PTV olmayan } \\
(n=103)\end{array}$ & $p$ \\
\hline Gestasyon yaşı, hafta* & $26.6 \pm 1.2$ & $28.8 \pm 3.1$ & 0.008 \\
\hline Doğum ağırlığı, gram* & $864 \pm 259$ & $1199 \pm 356$ & 0.001 \\
\hline Apgar, 1.dakika** & $3(1-7)$ & $5(1-9)$ & 0.63 \\
\hline Apgar, 5.dakika** & $4(1-8)$ & $5(2-9)$ & 0.54 \\
\hline Erkek, n(\%) & $13(86.7)$ & $82(79.6)$ & 0.48 \\
\hline $\mathrm{C} / \mathrm{S}, \mathrm{n}(\%)$ & 14(93.3) & $68(66)$ & 0.047 \\
\hline Preeklampsi, n(\%) & $2(13.3)$ & $21(20.4)$ & 0.28 \\
\hline Maternal diyabet, $n(\%)$ & $1(6.7)$ & $11(10.7)$ & 0.63 \\
\hline
\end{tabular}

Hastaların $104(\% 88,5)$ 'i prematürite ve respiratuar distress sendromu tanıları ile izleniyordu. Tromboz saptanan hastaların ortlama gestasyon yaşı ve doğum ağırlığı, saptanmayan hastalardan daha düşüktü (Tablo 1). Kateterlerin tamamı hastaların yenidoğan yoğun bakım ünitesine yatışının ilk günü takıımıştı. Tromboz saptanan bir hastada annede gestasyonel diyabet mevcuttu. Tromboz saptanan hastaların geç neonatal sepsis ve bronkopulmoner displazi oranları daha yüksekti ve hastanede yatış süresi daha uzundu. Yine bu grupta kateterin alçak yerleşim oranı daha fazla, kateter kalış süresi diğer gruba göre daha uzundu (Tablo 2).

Tromboz saptanan hastaların tamamı pediatrik hematoloji onkoloji birimi ile konsülte edildi. Ana portal vende trombozu olan hasaya antikoagülan tedavi başlandı. Takipte portal ven akımının sağlandığı belirlendi. Hiçbir hastada kısa ve orta dönemde komplikasyon saptanmadı.

Kateterlerin çıkarılma nedenlerine baktığımızda; 16 hasta sızdırma-kırıma, 6 hasta nekrotizan enterokolit ve diğer- 
lerinde de intiyaç kalmaması olarak belirlendi. Gruplar arasında kateterlerin çekilme nedenleri açısından fark yoktu

Tablo 2. Kateter özellikleri ve orta dönem morbiditeler

\begin{tabular}{|c|c|c|c|}
\hline & $\begin{array}{l}\text { PTV olan } \\
(n=15)\end{array}$ & $\begin{array}{l}\text { PTV olmayan } \\
(n=103)\end{array}$ & $p$ \\
\hline Kateter alçak yerleşim, $n(\%)^{* *}$ & $3(20)$ & $7(14.6)$ & 0.005 \\
\hline Kateterin kalış süresi,gün** & $14(5-15)$ & $10(2-16)$ & 0.043 \\
\hline Yatış süresi, gün** & $54(28-107)$ & $45(8-110)$ & 0.08 \\
\hline Geç neonatal sepsis, $n(\%)$ & $10(66.7)$ & $35(34)$ & 0.015 \\
\hline Prematüre retinopatisi, n(\%) & $3(20)$ & $5(48.5)$ & 0.063 \\
\hline Bronkopulmoner displazi, n(\%) & $4(26.7)$ & 12(11.7) & 0.039 \\
\hline
\end{tabular}

\section{Tartışma}

Neonatal PVT çocukluk çağında portal hipertansiyon ve ilişkili gastrointestinal sistem kanamalarının en önemli nedenidir. Damar duvarının mekanik hasarı tromboz oluşumunun ilk basamağını oluşturur ve umblikal ven kateteri PTV'nin en önemli risk faktörüdür $(6,7)$. Çalışmalarda umblikal ven kateterlerine bağı tromboz oranları değişkendir ve bu değişkenliğin nedeni tanı yöntemlerindeki ve USG kontrolü gerçekleştirme zamanı farkılıklarından kaynaklanabilir. Larroche ve ark. umblikal kateter takılmasını takiben 25-48 saat sonra PTV geliştiğini belirlemiştir. Bizim çalışmamızda da tromboz oranı \%9,9 olarak bulundu. Hastanemizde rutin olarak taburculuk öncesi portal doppler USG yapılmakta olup, erken dönemde USG gerçekleştirilmiş olsaydı bu oranın daha farklı olacağını düşünüyoruz.

Kateterin kalış süresi ve kateter ucunun bulunduğu yerin PVT ile doğrusal ilişkili olduğunu ileri süren çalışmalar bulunmaktadır (6-8). Bizim çalışmamızda ortanca kateter kalış süresi trombozu olan hastalarda daha uzundu. Umblikal venöz kateterler için iki haftaya kadar kullanım önerilmektedir (9). Yapılan bir çalışmada daha uzun kalış süresinin enfeksiyon ve tromboz ile ilişkili olduğu belirtilmiştir (10). Kateter ucunun yerleşim yerinin PVT için önemli bir risk faktörü olduğu belirtilmektedir. Çalışmamızda trombozu olan hastalarda kateter yerleşiminin daha yüksek oranda alçak tip yerleşimde olduğu gözlendi. Yüksek tip yerleşimde sağ atriyum ve inferior vena kavaya kan akışı daha fazla olduğundan PVT riskinin düştüğü öne sürülmektedir. Ancak kateter ucu pozisyonunun PVT'ye etki etmediği veya yüksek yerleşimde daha fazla görüldüğüne dair olan çalışmalar da vardır (11-12).

PVT'nin diğer olası risk faktörleri arasında umbilikal kord travması veya enfeksiyonu, hipoksemi, sepsis, konjenital malformasyonlar ve gestasyonel diabetes mellitus bulunur $(8,13)$. Umblikal ven kateterinin yerinde olup olmamasından bağımsız olarak, asfiksi, persistan pulmoner hipertansiyon, mekonyum aspirasyon sendromu, konjenital diyafragma hernisi, cerrahi acil durumlar veya konjenital kalp hastalıkları gibi ciddi altta yatan hastalığı olan tüm yenidoğanlarda PVT düşünülmelidir. Yine preterm bebek- lerde doğum ağılığı ve gestasyon yaşı düştükçe tromboz riski artmaktadır. Bizim çalışmamızda da trombozu olan hastaların doğum ağırlığı ve gestasyon yaşı trombozu olmayanlara göre daha düşüktü. Literatüre uygun olarak tromboza eğilim oluşturan düşük doğum ağırlığı, düşük gestasyon yaşı ve sepsis risk faktörleri bizim hastalarımizda da mevcuttu.

Neonatal kateter ilişkili asemptomatik trombozun klinik önemi henüz tam olarak anlaşılamamıştır. USG ile takipte trombozda spontan regresyon saptanmıştır (11).

Çalışmamızın bazı kısıttlıkları mevcuttur. Çalışmanın retrospektif olması en önemli sınırlılık olup, ikinci olarak hastalar tromboza eğilim oluşturan genetik faktörler açısından taranmamıştır. Ancak Revel-Vilk ve ark. kalıtsal protrombotik pıhtılaşma proteinlerinin yenidoğanlarda venöz tromboembolilerin patogenezine önemli bir katkı sağlamadığını; en önemli etyolojik risk faktörlerinin santral venöz hattın ve diğer tıbbi durumların varlığı olduğu sonucuna varmışlardır. PVT'nin uzun dönem komplikasyonlarından en önemlisi olan portal hipertansiyonun önemi nedeniyle uzun dönemli takip yapılmaması da başka bir kısıtııık oluşturmaktadır. Ancak hastalarımızın çoğunda sol portal ven dalında tromboz saptanmış olup, takipte sol hepatik lob atrofisi normalin varyantı olarak kabul edilmektedir $(14,15)$. Kim ve ark. Çalışmasında \%36. Morag ve ark. Çalışmasında \%22,5 karaciğer atrofisi rapor edilmiştir $(3,7)$.

PVT tedavisinde antikoagülan tedavinin rolü açık değidir. Bu konuda yenidoğanlar için hazırlanmış bir rehber bulunmamaktadır. Antikoagülanların risk ve yan etkileri göz önüne alınarak kişiselleştirilmiş tedavi yapılması önerilmektedir (12). Bu çalışmada ana portal vende tromboz saptanan hasta dışında antikoagülan tedavi başlanmamıştır. Ana portal vende tromboz saptanan hastaya ise enoksaparin tedavisi başlanmış ve takipte rekanalizasyon görülmüştür.

Sonuç olarak; PVT daha önce inanıldığı kadar nadir değildir ve tüm hasta yenidoğanlarda, özellikle de umblikal ven kateterli hastalarda düşünülmelidir. Uygun şekilde yerleştirilmiş bir umblikal ven kateteri daha iyi sonuçlarla ilişkilidir ve açık bir şekilde tercih edilir. PVT'nin potansiyel ciddi uzun dönem komplikasyonları nedeniyle erken tanı ve takip önemlidir. USG; PVT tanıSı alan tüm hastalarda tavsiye edilir.

\section{Kaynaklar}

1. Veldman A, Nold M.F, Behnke I.M. Thrombosis in the critically ill neonate: incidence, diagnosis and management. Vasc Health Risk Manag. 2008;4(6):1337-48.

2. Wigger H.J, Branselver B.R, Blanc W.A. Thromboses due to catheterization in infants and children. J Pediatr 1970;76(1):1-11.

3. Morag I, Epelman M, Daneman A, Moineddin R, Parvez B, Shechter T, Hellman J. Portal vein thrombosis in neonates: risk factors, course and outcome. J Pediatr. 2002;148(6):735-9.

4.Narang I. Review series: what goes around, comes around: childhood influences on later lung health? Long-term follow-up of infants with lung disease of 
prematurity. Chron Respir Dis 2010;7 (4):259-69.

5. Garner A. An international classification of retinopathy of prematurity. Pediatrics 1984;74 (1):127-33.

6. Alvarez F, Bernard O, Brunelle F, Hadchouel P, Odievre M, Alagille D. Portal obstruction in children, I: clinical investigation and hemorrhage risk. J Pediatr 1983;103(5):696-702.

7. Kim J.H, Lee Y.S, Kim S.H, Lee S.K, Lim M.K, Kim H.S. Does umbilical vein catheterization lead to portal venous thrombosis? Prospective US evaluation in 100 neonates. Radiology 2001:219(3):645-50.

8. Yadav S, Dutta A.K, Sarin S.K. Do umbilical vein catheterization and sepsis lead to portal vein thrombosis? A prospective, clinical, and sonographic evaluation. J Pediatr Gastroenterol Nutr 1993;17(4):392-6.

9. O'Grady N.P, Alexander M, Dellinger E.P, Gerberding J.L, Heard S.O, Maki D.G, Masur H, McCormick R.D, Mermel R.A, Pearson M.L, Raad I.I, Randolph A, Weinstein R.A. Guidelines for the prevention of intravascular catheterrelated infections. The Hospital Infection Control Practices Advisory Committee, Centers for Disease Control and Prevention, U.S. Pediatrics.2002;110(5):51.

10. Seibert J.J, Taylor B.J, Williamson S.L, Williams B.J, Szabo J.S, Corbitt S.L. Sonographic detection of neonatal umbilical artery thrombosis: clinical correlation. AJR Am J Roentgenol 1987;148(5):965-8.

11. Schwartz D.S, Gettner P.A, Konstantino M.M, Konstantino R.N, Bartley C.L Marc S.K, Ehrenkranz R.A, Jacops H.C. Umbilical venous catheterization and the risk of portal vein thrombosis. J Pediatr 1997;131(5):760-2.

12. Greenway A, Massicotte Monagle P, Monagle P. Neonatal thrombosis and its treatment. Blood reviews, 2004, 18(2): 75-84.

13. Scott J.M. latrogenic lesions in babies following umbilical vein catheterization. Arch Dis Child 1965;40(212):426-9.

14. Fraser-Hill M.A, Atri M, Bret P.M, Aldis A.E, Illescas F.F, Herschorn S.D. Intrahepatic portal venous system: variations demonstrated with duplex and color Doppler US. Radiology 1990;177 (2):523-6.

15. Hann L.E, Getrajdman G.I, Brown K.T, Bach A.M, Teitcher J.B, Fong Y, Blumgart L.H. Hepatic lobar atrophy: association with ipsilateral portal vein obstruction. AJR Am J Roentgenol 1996;167(4):1017-21. 